\title{
La mort et nous par la bande dessinée (suite)
}

\author{
Jean Martin
}

Dr méd., membre de la rédaction
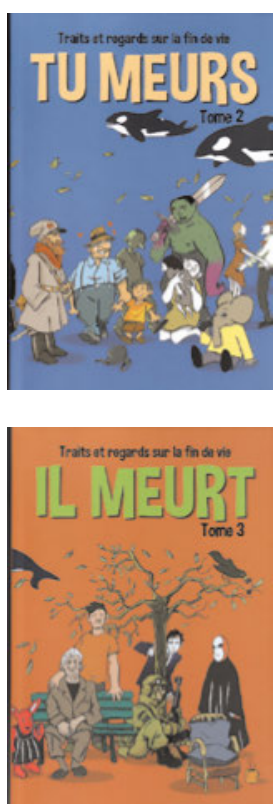

«Tu meurs» et «Il meurt» (Traits et regards sur la fin de vie - tomes 2 et 3 )

Vevey: Hélice Hélas Editeur et Fondation la Chrysalide; 2015.

60 pages chacun. $84 \mathrm{CHF}$ pour les trois volumes.

ISBN 978-2-940-52229-3

ISBN 978-2-9405-2228-6

La Fondation La Chrysalide, centre de soins palliatifs situé à La Chaux-de-Fonds et qui fait aujourd'hui partie de l'Hôpital Neuchâtelois, s'est donné la mission de promouvoir la qualité de l'accompagnement en fin de vie. Une équipe sous la direction du Dr Philippe Babando a conçu le projet d'une trilogie de bandes dessinées sur le thème de l'approche de la mort et de ses impacts sur les patients concernés et sur leurs proches. Un billet dans ce journal a évoqué en 2015 la première de ces BD [1].

Les tomes suivants ont le même format et la même présentation, avec chacun une douzaine de récits, dessinés par autant d'auteurs. Leurs "axes» sont indiqués par les titres: Tu meurs, on parle à/avec celui qui meurt, et Il meurt. Des styles graphiques variés, comme le sont les contenus. La plupart des contributions sont réalistes, portant sur des histoires qu'on rencontre quotidiennement. Plusieurs ont une dimension poétique et quelques-unes un caractère onirique: ainsi l'histoire d'un enfant cancéreux ou celle d'un jeune couple amoureux dont la femme meurt - en se noyant métaphoriquement. Quelques-unes restent énigmatiques.

\section{Des bandes dessinées qui peuvent utilement se prêter à la discussion des questionnements autour de la fin de vie.}

Mêlées à ces histoires où la mort survient, il y a des grossesses, ou de jeunes enfants. Comme dans le tome 1, les grands-parents occupent une place notable, avec le rapport aimant à leurs petits-enfants présents. S'ensuit, logiquement, le thème de la séparation de l'enfant de celui ou celle qui meurt. Un suicide. Quelques histoires en milieu médical. La visite en EMS d'un fils adulte à son père totalement mutique. Une illustration du parcours de vie de la conception à la mort, en quatre volets, chacun se terminant par la formule "Tu meurs» - entendue dans des sens différents selon les âges. Dans le tome 3 , à noter un intéressant échange entre une femme accompagnatrice de personnes en fin de vie et son fils adolescent. Et l'émouvante séparation, avec le rappel de tant de souvenirs, d'un couple âgé dont la femme meurt.

Comme dans le tome 1 , sont évoquées des situations de guerre (en décembre 2016, moment où ces lignes sont écrites, on pense au siège et à la chute d'Alep, en Syrie, dans des conditions humanitairement inadmissibles, scandaleuses - une autre est située à l'époque des armées à cheval). A deux reprises apparaissent des décès sur accident, en rapport avec la prise d'alcool.

Chacune de ces publications bénéficie d'une préface $\mathrm{du}$ Dr Babando. Celle du tome 2 est le récit attachant de l'altération progressive, par Alzheimer, de la santé d'une personne qui a été pour lui un grand-père d'adoption. Evoquant des questions souvent posées: «Comment vivais-tu ta maladie, cette déconnexion progressive de la réalité qui meublait la vie des autres? Que ressentaistu?». Puis: «Un jour tu as arrêté de marcher et tu es resté couché, puis tu n'as plus parlé; tu t'es lové dans ton lit et tu es resté encore quelque temps entre jour et nuit.» En terminant il rend hommage aux "personnes qui de près ou de loin prennent soin des personnes âgées et permettent souvent une fin de vie de bonne qualité et respectueuse des valeurs qui ont accompagné nos anciens pendant leur existence». La préface du tome 3 évoque une personne âgée parcourant les rubriques nécrologiques du journal («la page des morts»), en y retrouvant des personnes de sa connaissance.

Il faut saluer l'initiative prise par la Fondation La Chrysalide de mettre à disposition ces ouvrages qui, dans des cadres divers, peuvent utilement se prêter à la discussion des questionnements autour de la fin de vie.

\section{Référence}

1 Martin J. La mort et nous (par la bande dessinée) - Recension d'un ouvrage de la Fondation La Chrysalide - Tome 1, Bull méd. suisses 2015;96(35):1251 